\title{
Evaluation of the Clinical Effectiveness of High Frequency Left Prefrontal Repetitive Transcranial Magnetic Stimulation (rTMS) versus Electroconvulsive Therapy (ECT) in the Treatment-Resistant Depression (TRD)
}

\author{
Mansoor Malik ${ }^{1}$, Suneeta Kumari ${ }^{2, *}$, Stacy Doumas ${ }^{2}$, Saba Afzal ${ }^{2}$, Partam Manalai ${ }^{3}$, Gulparkha Manalai Osmani ${ }^{4}$ and Ramon \\ Solhkhah ${ }^{2}$
}

${ }^{1}$ Johns Hopkins Bayview Medical Center, Baltimore, Maryland, USA

${ }^{2}$ Ocean Medical Center, Hackensack Meridian School of Medicine, New Jersey, USA

${ }^{3}$ Psychiatric Institute of Washington, Washington, District of Columbia, USA

${ }^{4}$ Associated Professor, Department of Obstetrics and Gynecology, Kabul University of Medical Science, Kabul, Afghanistan

*Corresponding author: Suneeta Kumari, MD, MPH, Ocean Medical Center, Hackensack Meridian School of Medicine, New Jersey, USA, E-mail: Suneeta.kumari@hackensackmeridian.org

Received: 11 Mar, 2020 | Accepted: 08 Feb, 2021 | Published: 16 Feb, 2021

Citation: Malik M, Kumari S, Doumas S, Afzal S, Manalai P, et al. (2021) Evaluation of the Clinical Effectiveness of High Frequency Left Prefrontal Repetitive Transcranial Magnetic Stimulation (rTMS) versus Electroconvulsive Therapy (ECT) in the Treatment-Resistant Depression (TRD). J Psychiatry Ment Health 6(1): dx.doi.org/10.16966/2474-7769.140

Copyright: (c) 2021 Malik M, et al. This is an open-access article distributed under the terms of the Creative Commons Attribution License, which permits unrestricted use, distribution, and reproduction in any medium, provided the original author and source are credited.

\section{Abstract}

Major Depressive Disorder (MDD) is a highly prevalent, persistent, and disabling mental illness. Statistically, the lifetime prevalence of depression is $17 \%$, but only $6 \%$ of those living with depression receive standard treatments. ECT has a long track record of success; it is one of the oldest forms of treatment for TRD. On the other hand, rTMS is a non-invasive, painless stimulation of the Central Nervous System (CNS) used to treat TRD.

Objective: To compare the effectiveness of two neuro-stimulation techniques, ECT and rTMS, to treat TRD.

Methods: Randomized Clinical Trials (RCT) was identified by searching MEDLINE, PubMed, and EMBASE. The selection of the study was performed by utilizing the Preferred Reporting Items for Systematic Reviews and Meta-Analysis (PRISMA). The Hamilton Depression Rating Scale (HDRS-21) was used to quantify depression severity. This meta-analysis included a total of 11 RCTs which included total number of patients (450) in both ECT and rTMS groups.

Results: The mean reduction in HDRS score was 0.2802 higher in ECT than rTMS with the confidence interval (-0.8432 to 1.4037$)$, including a mean difference of 0 . An analysis of the heterogeneity performed using Cochrane's Q-statistics showed that a mean decrease in HDRS was significant (Cochrane's $Q=56.73 ; d f=10 ; p<0.05$ ), $12=83.2 \%$.

Conclusion: TRD continues to be a significant clinical challenge. The heterogeneity of the specific patient populations and study designs makes it more challenging to compare these therapies directly. There is a pressing need for large-scale, adequately powered studies to draw definite conclusions.

Keywords: Depression; Transcranial magnetic stimulation; Treatment-resistant depression; Electroconvulsive therapy; Randomised controlled trial

Abbreviations: ECT: Electroconvulsive Therapy; rTMS: Repetitive Transcranial Magnetic Stimulation; UL: Unilateral; BL: Bilateral; HDRS: Hamilton Depression Rating Scale; BPRS: Brief Psychiatric Rating Scale; GAF: Global Assessment of Function Scale; GDR: Global Depression Scale; PSQI: Pittsburg Sleep Quality Index; MMSE: Mini Mental State Examination; BDI: Beck Depression Inventory; VAS: Visual Analogue Scale; CGI: Clinical Global Impressions; CAMCOG: Cambridge Cognitive Examination scores

\section{Background}

Depression is a serious mental illness. Several studies conducted by the Global Burden of Disease (GBD): Institute of health metrics and evaluation from 1990 to 2010 show MDD to be a leading cause of economic burden. In their 2010 study, MDD accounted for $8.2 \%$ of global YLDs [1]. Major Depressive Disorder (MDD) is a chronic or recurrent psychiatric disorder that is associated with high morbidity, and presents as a big financial burden. Accumulating evidence has suggested that $48 \%$ of patients suffering from depression have had suicidal thoughts, and $24 \%$ of those have attempted suicide [2].
Treatment-Resistant Depression (TRD) is quite common, occurring in up to one-third of MDD patients [3]. It is estimated that TRD accounts for approximately $\$ 64$ billion of the total cost of depression $[4,5]$. Due to the chronic nature of TRD and its limited treatment options, TRD is accountable for a disproportionate amount of the disease burden.

Treatment-Resistant Depression (TRD) refers to the concept regarding the burden and impact of depression due to its resistance to treatment. Moreover, defining TRD mentioning the characterization of depression. The American Psychiatric Association describes in the 
DSM-5 that MDD is not particularly one disorder, but a combination of symptoms and patient profiles. However, many authors include that the impact of MDD on TRD influence economic situations significantly. TRD is often associated with suicidality and with nonsuicidal mortality and may result in a request for euthanasia/assisted dying in some countries.

When it comes to elaborate the definition of TRD-there is no validated consensus definition of TRD. At a minimum, TRD signifies depression that has failed to respond to at least one optimally administered therapy. Regulatory authorities such as the European Agency for the Evaluation of Medicinal Products have defined TRD as failure to respond to two products of different classes, used for a sufficient length of time at an adequate dose, without specification of an insufficient dose or duration. The USFDA has not defined TRD; instead, FDA approved devices or medication describes the specific patient population investigated in pivotal trials to evaluate the safety and efficacy of medications and devices [6].

It is estimated that 17 million people in the U.S. suffer from depression [7]. Antidepressant medications have been the mainstay of depression treatments since the 1950s. Even with the availability of many alternative antidepressant agents, TRD continues to be a severe problem. It is estimated that $30 \%$ to $50 \%$ of patients with major depression fail to respond to an initial course of antidepressant therapy. In the Star ${ }^{\star} \mathrm{D}$ study, considering all options, remission rates for the second-step treatments were a discouraging $25 \%$, amounting to an overall response rate of about $50 \%-55 \%[8,9]$. Today, ECT is considered an acceptable treatment for TRD, and its efficacy and safety are well established in research. At the same time, rTMS is mostly preferred by patients because it is non-invasive, easy to administer, and fewer side effects.

\section{Electro-Convulsive Therapy (ECT)}

ECT is the most extended-standing psychiatric treatment done under anesthesia for patients with TRD. Having been available for over 79 years, ECT has a long track record of success. Over its long course of use, ECT has been sufficiently refined and considered to be a safe and effective treatment for TRD. The most significant concern regarding ECT is that of potential memory loss. About $75 \%$ of all patients who are given ECT develop memory impairment [10]. However, follow-up studies indicate that almost all patients who do experience memory impairment do return to their cognitive baseline after six months of treatment [11].

Rose D, et al., found that at least one-third of patients reported significant memory loss after going through ECT $[11,12]$. For most patients, the memory loss was limited to short-term retrograde and anterograde amnesia, lasting anywhere from a few hours to a few days. Such amnesia is usually not very troublesome; nevertheless, recent developments in ECT techniques, including ultra-brief pulse stimulation, provide a less adverse effect on cognition. Both the ultrabrief stimulus and right unilateral electrode placement produced less short and long-term retrograde amnesia [13]. In one study, a patientrated their memory deficit as less severe following ultra-brief right unilateral ECT compared to treatments of ultra-brief bilateral ECT and standard pulse width unilateral ECT $(\mathrm{p}<0.001)$ [14].

\section{Repetitive Transcranial Magnetic Stimulation (rTMS)}

rTMS was introduced by Barker AT, et al. [15] in 1985 as a noninvasive, painless stimulation of the central nervous system. rTMS initially used in neurology for studies of nerve conduction; it was not until later when it caught the attention of psychiatrists who were interested in exploring other, less invasive methods to treat TRD.
Although rTMS also uses electromagnetic energy to stimulate specific brain circuits, it differs significantly from ECT. Unlike ECT, which does not focus on any region of the brain, rTMS is localized mainly to the Left Dorsolateral Prefrontal Cortex (DLPFC). Moreover, unlike ECT, patients do not require anesthesia for rTMS; it can be easily administered and is associated with little to no memory disturbances or cognitive side effects [16]. rTMS may cause common side effects such as auditory impairment, headaches, seizures, or twitching of facial muscles. Furthermore, the relapse rate in patients of rTMS and ECT was recorded over six months and has been reported in a clinical trial to be similar at about 20 percent for both forms of treatment [17].

\section{Mechanism of action}

ECT works through electric currents that are passed through the brain under general anesthesia. This results in a brief, controlled seizure that affects neurons and chemicals in the brain. While TMS does not work through an epileptic seizure; instead, it creates magnetic fields to stimulate nerve cells in the brain to improve symptoms of depression. With TMS, a large electromagnetic coil is placed on a person's forehead, and short pulses are directed into the brain's area believed to control moods. Generally, the rTMS treatment preference is higher than that of ECT.

\section{Cost effectiveness of ECT and TMS}

The cost of the ECT is higher than that of rTMS (\$2075 vs. \$814). Overall, research suggests that ECT is more effective than rTMS for TRD, while patients tend to prefer rTMS, as most insurance providers cover it, has fewer side effects. It is much easier to administer [18].

Through an economic evaluation, ECT alone found to be less costly on average with more effectiveness than rTMS thorough analysis produced by the Markov model, which stimulates the costs and health outcomes of individuals under certain conditions over 12 months [19]. Another perspective is utilized through the Spanish National Health Service by exposing rTMS followed by ECT, which does not include family contributions or productivity loss [19].

\section{Methods}

This meta-analysis was conducted by authors who independently reviewed each study. The literature was searched for RCTs on ECT and rTMS for the TRD from July 2000 to July 2017. This meta-analysis is performed according to the PRISMA approach in the selection of the studies (Figure 1). The literature search identified 69 studies published in English on PubMed, EMBASE, and MEDLINE. Additional records are identified through other sources, including Google Scholar and Research Gate $(n=11)$. After the removal of duplicates, 65 articles were screened. Of these, 23 studies were excluded based on titles or abstracts that did not meet some or all the inclusion criteria. Full-text articles (Listed below) were assessed for eligibility $(n=42)$. Full-text articles were excluded with reasons $(n=31)$. Studies conducted on the efficacy of ECT and rTMS among patients with other psychiatric diagnoses (Schizophrenia, anxiety disorder, ADHD) were also excluded. Besides, randomized, single-blind controlled studies that administered rTMS only were excluded. This meta-analysis included 11 RCTs and the total number of patients (450) in both ECT and rTMS groups.

\section{PRISMA approach}

The key search terms used to search for literature included "RCTs on ECT and rTMS, MDD, TRD." To be included in the meta-analysis, the following study inclusion criteria were set up: 
- RCT's published in English through various scientific journals.

- Studies must be conducted on human subjects, both male and female.

- Subjects for the studies must have given informed consent.

- Studies comparing ECT and rTMS in the treatment of TRD met DSM-IV criteria for unipolar depression with or without psychotic features. And the TRD defined in those studies as "failure to respond to two products of different classes, used for a sufficient length of time at an adequate dose."

- Studies used left prefrontal high frequency rTMS.

- Studies reported sample size, gender distribution, the mean reduction in HDRS score, and standard deviation (S.D.) included.

- This meta-analysis included only RCTs which used HDRS as the primary outcome measure.

Each study was thoroughly reviewed and evaluated to get a better understanding of the results regarding the effectiveness of the two treatment modalities. The abstract of each study reviewed initially, followed by a detailed, comprehensive review of the entire study to ensure studies met the selection criteria.

After the completion of the database search, a summary of each article was tabulated under the following headings: author names, year of publication, the sample size for TMS and ECT, gender distribution, duration of treatment, and the list of psychometric tools used for assessment of the severity of depression and whether or not psychotropic medication was withheld.

\section{Statistical analysis}

Data extraction: The mean reduction in HDRS estimated from RCT and the $95 \%$ CI of ECT and rTMS outcomes associated with the reduction in the mean HDRS were compared for both treatments. The data were extracted from each RCT to compute effect size for each study and a forest plot to evaluate overall effect size of combined studies.

A fixed-effects model: This is a statistical model in which the model parameters are fixed or non-random quantities. This is in contrast to random-effects models and mixed models in which all or some of the model parameters are considered as random variables. Random and fixed effect models are two popular statistical models that are utilized in meta-analysis. These models aim to provide a general framework regarding the interpretation of the statistics [20].

Combined effect size for ECT and rTMS studies: Fixed and Random Effect Model was used. The results from a random effect, as well as a fixed effect, models are also presented in this meta-analysis for the sake of comparison. The mean reduction in HDRS was 0.2802 higher in ECT, relative to TMS. However, this was not statistically significant since the confidence interval (-0.8432 to 1.4037$)$ included a mean difference of 0 . The random effect model displayed a more significant effect size (i.e., 95\% confidence interval of $1.1958 \pm 2.8914$ ). This was also not statically significant. Based on this observation, we can conclude that, clinically, ECT is more effective than TMS. However, statistically, there is no difference between the two treatment modalities.

Statistical analysis and graphics were both computed with $\mathrm{R}$-software. The effect size examined in this study was the difference in the mean reduction in HDRS. The summary (pooled) mean reduction in HDRS was generated using random-effects model to account for within and across-study variation to exposure. The summary and individual studies' mean reduction in HDRS was represented as point estimates with $95 \%$ CI on a forest plot.

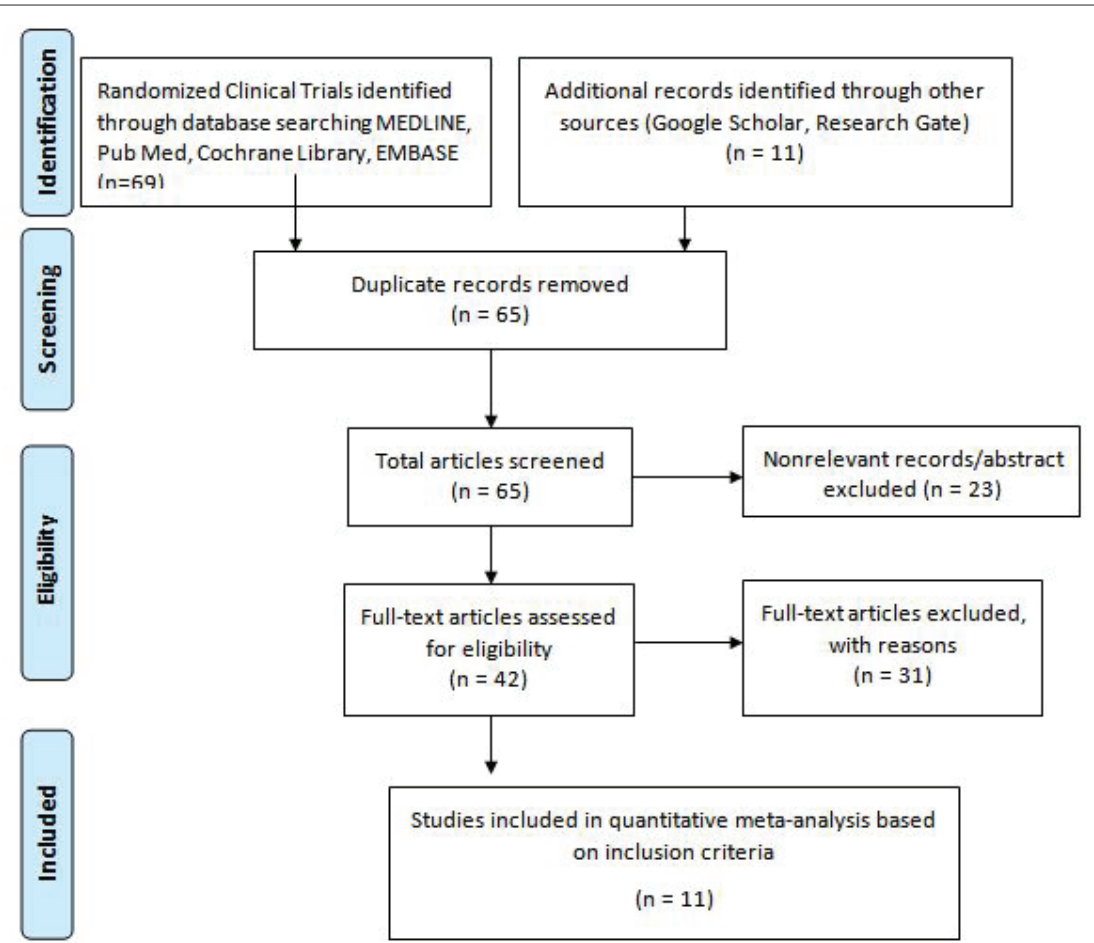

Figure 1: PRISMA* flow chart-meta-analysis of RCTs on ECT and TMS. 


\section{Qualitative analysis}

Table 1 displays a summary of the 11 articles that were used to investigate the effectiveness of ECT and rTMS among patients with TRD. These RCT satisfied all the inclusion criteria for meta-analysis $[10,14,16,21-28]$.

\section{Quantitative analysis (Forest plot-random effect model)}

Figure 2 shows the forest plot of the random effect model of all 11 studies combined effect sizes. This pooled statistical estimate exhibits an overall comparison of effectiveness of ECT and TMS in improving TRD. The combined summary of effect size is 1.20 with CI $(-1.70$, 4.09), which is not statistically significant between ECT and rTMS. TMS HDRS Reduction Greater (Favors TMS) ECT HDRS Reduction Greater (Favors ECT).

Two studies conducted by Mcloughlin DM, et al. [10] and O'Connor $\mathrm{M}$, et al. [24] indicate ECT is more effective than rTMS while another study done by Keshtkar M, et al. [28] showed that rTMS is more effective than ECT. Keshtkar M, et al. [28] study revealed that the reduction in the score of suicidal sub-scale of HDRS was substantially greater in the ECT group than in the rTMS. The rest of the studies did not show any significant differences.

The results from random effect, as well as fixed effect, models are also presented in this meta-analysis for the sake of comparison (Table 2). The mean reduction in HDRS was 0.2802 higher in ECT, relative to TMS, however, this was not statistically significant since the confidence interval (-0.8432 to 1.4037) included a mean difference of 0 . The random effect model displayed a greater effect size (i.e. $95 \%$ confidence interval of $1.1958 \pm 2.8914)$ this was also not statically significant. Based on this observation we can conclude that, clinically, ECT is more effective than TMS. However, statistically, there is no difference between two treatment modalities.

In order to decide on the appropriateness of the random effect and of the fixed effect model, an analysis of heterogeneity was performed

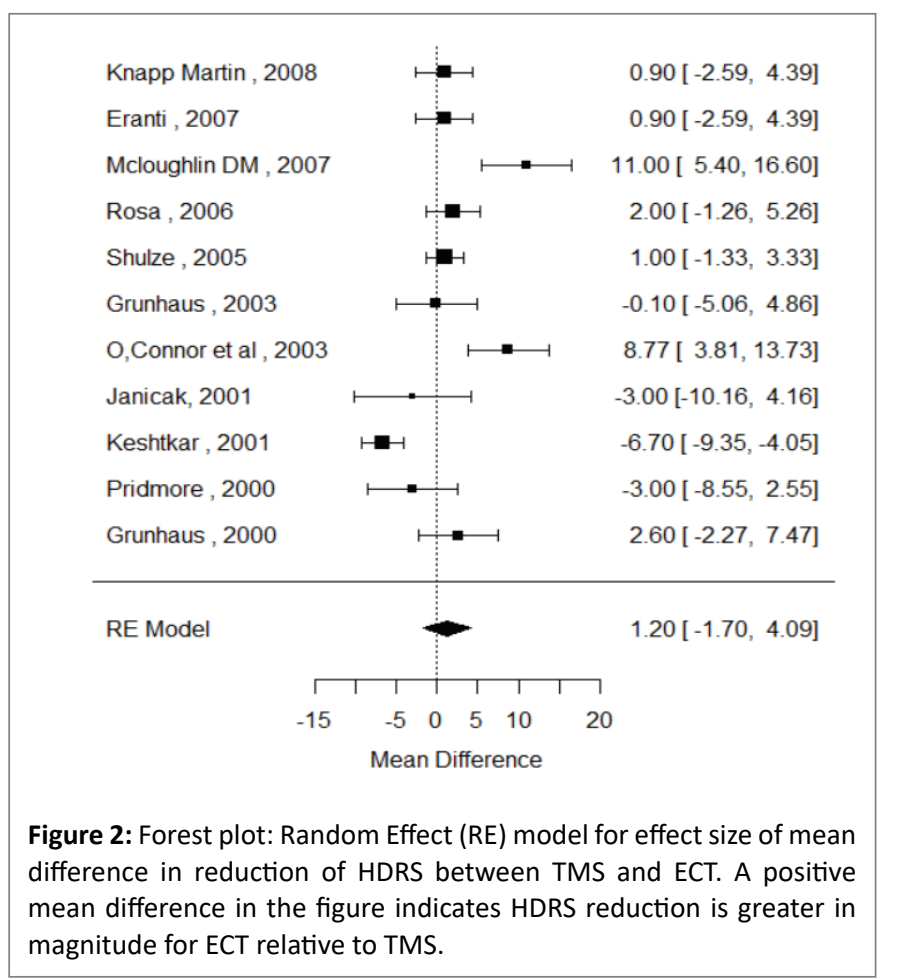

using Cochrane's Q-statistics, indicating that the test for heterogeneity of the mean reduction in HDRS was significant (Cochrane's $Q=56.73$, $\mathrm{df}=10, \mathrm{p}<0.05, \mathrm{I} 2=83.2 \%)$. This suggests that all studies have a common true effect size, thus revealing a high degree of heterogeneity in the effect sizes of the component studies. Based on these findings, authors concluded that the random effect model was a better model to summarize the combined effect size.

The meta-analysis investigates the hypothesis that the effect size of mean HDRS reduction is statistically significantly different between ECT and TMS. To this extent, the null hypothesis is the mean difference in HDRS reductions between the two therapies (ECT reduction minus TMS reduction) is zero. Given the random effect models ascertained $p>0.05$, there is not enough evidence to reject this null hypothesis and it cannot be said that the mean difference in HDRS reduction between ECT and TMS is statistically significant.

\section{Assessment of publication bias}

The publication bias was assessed by construction and inspection of funnel plots-that is, plot of the logarithm of the mean reduction in HDRS against the logarithm of the standard error of the mean.

A visual inspection of the constructed funnel plots (Figure 3) shows that most of the studies, except for three studies Mcloughlin DM, et al., O'Connor M, et al., and Keshtkar M, et al., [10,24,28] study were within confidence limits, confirming symmetry and supporting evidence of a lack of publication bias. However, the three studies outside the funnel were in fact the only three studies that demonstrated a statistically significant difference between ECT and TMS. Among the three studies performed, Mcloughlin DM, et al. and O'Connor M, et al. [10,24] demonstrated that ECT was more efficacious than TMS with respect to HDRS score reduction, whereas the Keshtkar M, et al. [28] study indicated the contrary with statistical significance.

\section{Discussion}

The goal of this review is to compare the effectiveness of two neurostimulation techniques ECT and rTMS for the treatment of TRD. The mean reduction in the HDRS score was 0.2802 higher in ECT relative to rTMS with the confidence interval (-0.8432 to 1.4037), including a mean difference of 0 . An analysis of the heterogeneity was performed using Cochrane's Q-statistics that showed that a mean decrease in HDRS was significant.

Additionally, the selection of studies population is varied in previous studies; initial RCTs suggested ECT is more effective in treating MDD with psychotic features than with nonpsychotic features [17]. Nevertheless, because MDD patients with psychotic, suicidal elements respond poorly to antidepressant pharmacotherapy alone, ECT should be considered first-line therapy for pt. with this disorder.

The findings from a new study suggest- for patients with psychotic depression, response to treatment, remission rates, and cognitive improvement are better following Electro-Convulsive Therapy (ECT) than for patients with nonpsychotic depression. These differences may be because psychotic patients are referred for ECT earlier in the disease course [29].

There are only a handful of studies comparing rTMS directly to ECT, as summarized in table 1. Each of these studies used random allocation and blind raters. Most of the studies used more significant than ten rTMS sessions (range 10.8 to 20 ) with high-frequency pulses ranging from $5-20 \mathrm{~Hz}$ and with a wide range of pulses per session ranging from 400 to 15000 pulses. The numbers of failed medication trials among included studies were varied significantly. Overall, these 


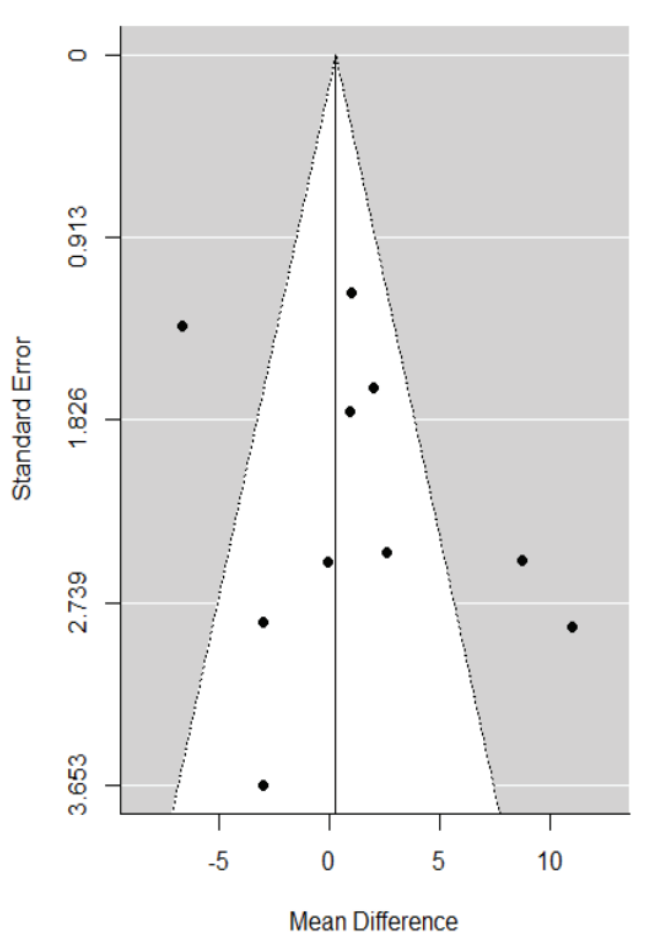

Figure 3: Funnel plot for mean-difference in HDRS reduction between TMS and ECT. A positive mean difference implies ECT had a greater positive impact on HDRS reduction than TMS.

studies represented the severely depressed population with a mean duration of current episode ranging from 10.4 to 66.4 weeks.

Most of these studies did not show apparent statistical differences in response rate between ECT and rTMS. Additionally, some studies used bilateral, and some used unilateral model. We found variability in the studies in terms of measuring the cognitive functions. Some studies have used scoring to report cognitive function (CAMCOG: Cambridge cognitive Examination scores; MMSE: Mini-Mental State Examination), while other studies did not measure the cognitive process. The most reported side effects were headaches, muscle soreness, and nausea, and cognitive deficit.

All RCTs included in this meta-analysis utilized HDRS to quantify depression symptomatology. The HDRS, once considered to be the "gold standard", is widely used to measure the effectiveness of antidepressant effects of ECT and TMS, but in the 1990s, its use began to be questioned. The central review of 70 studies suggested that interrater and retest reliability are adequate for the global score but are weaker for individual items. In another study, HDRS compared to Beck Depression Inventory (BDI)-a meta-analysis suggested that after treatment, the HDRS was more "sensitive to change" on retesting; this could be the reason why HDRS has widely used in clinical trials [30].

According to gathered findings from the last meta-analysis [31], higher percentages of patients demonstrated an improvement in HDRS score (primary outcome) on ECT than on TMS. However, ECT uses limited by several disadvantages, including the lack of access in many areas; it can be difficult to find practitioners and facilities that offer ECT as a treatment. ECT is also associated with a negative public image due to the negative stigma [18].

\section{Limitations}

Certain drawbacks limit this meta-analysis. One limitation is that few studies were available to examine and compare the therapeutic effect of ECT and rTMS for TRD. Moreover, the meta-analysis limited to manuscripts written in English, thus excluded potentially viable papers in other languages. One crucial observation noticed in this meta-analysis was that several studies mentioned the number of dropouts yet failed to mention the reasons behind this. It is essential to reveal why drop-outs and why and how missing data were analyzed since this may have impacted the results. Despite these limitations, this study supports the clinical impression that ECT is more effective than rTMS for treating TRD. Moreover, in one study, ECT was carried out according to a standard clinical application, whereas treatment with rTMS took place in the context of a research protocol. This difference might have influenced the results in favor of ECT [29].

The main limitation of this meta-analysis is small sample sizes with a limited number of participants (25-73), therefore, findings from this meta-analysis makes the generalization of results difficult. Some possible reasons that could have led to smaller sample sizes are inaccessibility to rTMS, a lack of referral from a provider or unfamiliarity with the new techniques as rTMS was still a new practice when those studies were conducted. As the use of rTMS gaining popularity and traction, future studies should focus on the utilization of larger samples, allowing for the identification of advanced uses and benefits of rTMS in clinical practice.

Additionally, the studies included in this meta-analysis were randomized and controlled. However, most of the authors in these studies have reported that due to the assumed variation in severity of the depression, it was ethically unjustifiable to have a placebo group. This lack of a control group could be a limiting factor in identifying the efficacy of the ECT and rTMS groups.

\section{Future Directions}

\section{Short term and long-term effects of ECT and rTMS}

Generally, in any treatment it is imperative to consider the overall effectiveness as well as safety and tolerability issues. To date, none of the study has compared short term and long-term side effects of ECT and rTMS; this would be an important area for future research to estimate risk/benefit analysis of the two treatment modalities, so clinicians can choose the most effective treatment for patients.

The most common problem when dealing with rTMS is discomfort or pain at the application, which occurs due to intense magnetic pulses applied over the DLPFC. Due to the rich innervations in this area, trigeminal nerve stimulation causes contraction of muscles around the eye, sensations in the nose and teeth, or tearing. Some patients experience tension type headache due to muscle contraction. These side effects generally subside gradually within a few weeks. During the first few treatment sessions, the use of analgesics (e.g., Aspirin, Acetaminophen, Ibuprofen) as a pretreatment may preclude the headaches.

The incidence of seizure appears to occur approximately $0.1 \%$ of the time over an entire course of rTMS treatments. This is the most serious potential adverse effect of rTMS, yet it resolves spontaneously with supportive therapy and does not result in any long term neurological or medical complications. A prior history of seizures is a relative contraindication to the use of rTMS [32].

Cognitive side effects of ECT are also an important issue; however, most literature lacks a comprehensive comparison of these side effects. 
Table 1: RCTs on ECT and TMS.

\begin{tabular}{|c|c|c|c|c|c|c|}
\hline Study Name & $\begin{array}{c}\text { Participant } \\
\text { Characteristics }\end{array}$ & ECT Protocol & $\begin{array}{c}\text { TMS } \\
\text { Protocol }\end{array}$ & Outcomes & Psychotropics Meds & Comments \\
\hline $\begin{array}{l}\text { Grunhaus L, et } \\
\text { al. [16] }\end{array}$ & $\begin{array}{l}\text { Mean age (S.D): } \\
\text { ECT: } 63.6 \text { (15) } \\
\text { TMS: } 58.4 \text { (15.7) } \\
\text { N=40 } \\
\text { ECT: } 20 \\
\text { TMS: } 20 \\
\text { Pts. with psychosis } \\
\text { included: ECT 10, } \\
\text { TMS } 9 \\
\text { Duration of episode } \\
\text { (weeks): } \\
27.4 \text { (ECT) } \\
33.2 \text { (TMS) } \\
\text { Previous episodes } \\
\text { (months): } \\
2.4 \text { (ECT) } \\
2.3 \text { (TMS) }\end{array}$ & $\begin{array}{l}\text { Mean treatments: } \\
9.6 \\
12 \text { received RUL ECT } \\
8 \text { started from RUL } \\
\text { but switched to BL } \\
\text { ECT } \\
2.5 \times \text { ST }\end{array}$ & $\begin{array}{l}90 \% \mathrm{MT} \\
\text { Pulse frequency: } \\
10 \mathrm{~Hz} \\
\text { Train duration: } 2 \text { to } \\
6 \mathrm{sec} \\
\text { Pulses per session: } \\
400-1200 \\
\text { Total sessions: } 20\end{array}$ & $\begin{array}{l}\text { HDRS } \\
\text { BPRS } \\
\text { GAF } \\
\text { GDR } \\
\text { PSQI } \\
\text { MMSE }\end{array}$ & $\begin{array}{l}\text { ECT Group: Psychotropic } \\
\text { meds were continued } \\
\text { and pts were stable } \\
\text { during ECT sessions. } \\
\text { TMS Group: All } \\
\text { psychotropic } \\
\text { medications were } \\
\text { discontinued. } \\
\text { Clonazepam 1-2 mg/ } \\
\text { day given in two divided } \\
\text { doses to decrease } \\
\text { anxiety, relieve severe } \\
\text { insomnia and occurrence } \\
\text { of seizures. }\end{array}$ & $\begin{array}{l}\text { Overall ECT had a higher } \\
\text { response rate (50\% } \\
\text { reduction in HDRS and } \\
60 \% \text { in GAF). However, } \\
\text { the comparison of the } \\
\text { two groups with ANOVA } \\
\text { did not show significant } \\
\text { differences. } \\
\text { ECT was clearly superior } \\
\text { to TMS on all clinical } \\
\text { measures for ECT (73.3 } \\
\% \text { vs. } 27.5 \% \text { reduction in } \\
\text { HDRS, p=0.005). } \\
\text { No difference was } \\
\text { recorded in cognitive } \\
\text { effects of two groups } \\
\text { using repeated } \\
\text { measures ANOVA. }\end{array}$ \\
\hline $\begin{array}{l}\text { Pridmore S, et } \\
\text { al. [21] }\end{array}$ & $\begin{array}{l}\text { Mean age (S.D): } \\
\text { ECT: } 41.5 \text { (12.9) } \\
\text { TMS: } 44.0 \text { (11.9) } \\
\text { N=32 } \\
\text { ECT: } 16, \\
\text { TMS: } 16 \\
\text { Treatment resistant } \\
\text { Psychotic patients } \\
\text { excluded } \\
\text { Duration of episode } \\
\text { (weeks): } \\
25.6 \text { (ECT) } \\
30.4 \text { (TMS) }\end{array}$ & $\begin{array}{l}\text { RUL } \\
504 \mathrm{mC} \\
100 \% \text { machine } \\
\text { output } \\
\text { Man treatments: } 6.2\end{array}$ & $\begin{array}{l}\text { 100\% MT } \\
\text { Pulse frequency: } \\
20 \mathrm{HZ} \\
\text { Train Duration: } \\
2 \mathrm{sec} \\
\text { Pulses per session: } \\
1200-1400 \\
\text { Total sessions: } \\
10-14 \\
\text { Mean: } 12.2\end{array}$ & $\begin{array}{l}\text { HDRS } \\
\text { BDI } \\
\text { Mood Rating } \\
\text { VAS } \\
\text { Side Effects } \\
\text { Rating Scale }\end{array}$ & $\begin{array}{l}\text { All concurrent } \\
\text { medications were } \\
\text { continued. }\end{array}$ & $\begin{array}{l}\text { Overall advantage } \\
\text { for ECT group on } \\
\text { multivariate analysis } \\
\text { ( } p=0.044) \text {. However, no } \\
\text { statistical difference in } \\
\text { HDRS scores between } \\
\text { the two groups } \\
\text { ( } p=0.278 \text { ). } \\
\text { ECT group had } \\
\text { significantly lower } \\
\text { BDI ratings than the } \\
\text { TMS group, with } \\
\text { improvements of } 69.1 \% \\
\text { vs. } 45.5 \% \text { ( } p=0.027) . \\
\text { Overall remission } \\
\text { (HDRS<8) were equal in } \\
\text { both groups (68\%). }\end{array}$ \\
\hline $\begin{array}{l}\text { Janicak PG, et } \\
\text { al. [22] }\end{array}$ & $\begin{array}{l}\text { Mean age (S.D): } \\
\text { ECT: } 42.73 \text { (14) } \\
\text { TMS: } 42.87 \text { (12.9), } \\
\text { N=25 } \\
\text { ECT 13, TMS } 12 \\
\text { Psychosis: } \\
\text { ECT: 6, TMS: } 3 \\
\text { Length of episode } \\
\text { (weeks): } \\
22.2 \text { (ECT) } \\
12.67 \text { (TMS) } \\
\text { Age of onset: } \\
29.2 \text { (ECT) } \\
25.38 \text { (TMS) }\end{array}$ & $\begin{array}{l}\mathrm{BL} \\
\text { 3-12 treatments }\end{array}$ & $\begin{array}{l}\text { 100\% MT } \\
\text { Pulse Frequency: } \\
10 \mathrm{~Hz} \\
\text { Train Duration: } \\
5 \mathrm{sec} \\
\text { Pulses per session: } \\
1000 \\
\text { Total sessions: } \\
10-20\end{array}$ & $\begin{array}{l}\text { HDRS } \\
\text { BPRS } \\
\text { YMS } \\
\text { CGI }\end{array}$ & $\begin{array}{l}\text { Subjects on anxiolytics } \\
\text { were given medication } \\
\text { as needed and attempt } \\
\text { was made to tapper } \\
\text { it. Three received } \\
\text { Clonazepam during } \\
\text { the study. Three ECT } \\
\text { subjects received anti- } \\
\text { psychotics for part of the } \\
\text { treatment. } \\
\text { rTMS subjects did } \\
\text { not receive any anti- } \\
\text { psychotics medication. }\end{array}$ & $\begin{array}{l}\text { Equivalent improvement } \\
\text { in ECT and TMS groups. } \\
\text { Response rate ( } 50 \% \\
\text { reduction in HDRS } \\
\text { core, final score }<10 \\
\text { or final GAF }>60 \text { ) was } \\
56 \% \text { in ECT group and } \\
46 \% \text { in TMS group. } \\
\text { The difference was not } \\
\text { significant (Fisher exact } \\
\text { test, p=ns). } \\
\text { Data for psychotic } \\
\text { patients were not } \\
\text { analyzed separately. }\end{array}$ \\
\hline
\end{tabular}




\begin{tabular}{|c|c|c|c|c|c|c|}
\hline $\begin{array}{l}\text { Grunhaus L, et } \\
\text { al. [23] }\end{array}$ & $\begin{array}{l}\text { Mean Age (S.D): } \\
\text { ECT } 61.4 \text { (16.6) } \\
\text { TMS } 57.6(13.7) \\
\text { N=40, ECT 20, TMS } \\
20 \\
\text { Psychotic patients } \\
\text { excluded } \\
\text { Duration of episode } \\
\text { (weeks): } \\
46 \text { (ECT) } \\
66.4 \text { (TMS) }\end{array}$ & $\begin{array}{l}\text { RUL switched to BL } \\
\text { (if no response after } \\
6 \text { treatments). } \\
2.5 \times \mathrm{ST} 13 \text { had RUL } \\
\text { and } 7 \text { had BL ECT. } \\
\text { Mean treatment: } \\
10.25\end{array}$ & $\begin{array}{l}90 \% \mathrm{MT} \\
\text { Pulse frequency: } \\
10 \mathrm{~Hz} \\
\text { Train Duration: } \\
6 \mathrm{sec} \\
\text { Pulses per Session: } \\
1200 \\
\text { Total Sessions } 20\end{array}$ & $\begin{array}{l}\text { HDRS } \\
\text { BPRS } \\
\text { GAF } \\
\text { GDR } \\
\text { PSQI } \\
\text { MMSE } \\
\text { MATS }\end{array}$ & $\begin{array}{l}\text { Patients in both groups } \\
\text { were progressively } \\
\text { withdrawn from } \\
\text { Lorazepam medications. } \\
\text { Patients were } \\
\text { occasionally allowed to } \\
\text { take Brotizolam (a short } \\
\text { acting benzodiazepine) } \\
\text { for sleep induction. }\end{array}$ & $\begin{array}{l}\text { No differences in ECT } \\
\text { and rTMS groups on } \\
\chi^{2} \text { test. The response } \\
\text { rate for the ECT group } \\
\text { was } 60 \% \text { and for the } \\
\text { TMS group was } 55 \% \\
\left(\chi^{2}=0.01 \text { ). }\right. \\
\text { Remission rate (HDRS }<8 \text { ) } \\
\text { was } 30 \% \text { in both groups. } \\
\text { No statistical difference } \\
\text { in BPRS, GAF, GDR, PSQI, } \\
\text { MMSE scoring. }\end{array}$ \\
\hline $\begin{array}{l}\text { O'Connor M, et } \\
\text { al. [24] }\end{array}$ & $\begin{array}{l}\text { Mean Age (S.D) } \\
\text { ECT: } 48.4 \text { (12) } \\
\text { TMS: } 51.2(12.2) \\
\text { N=28 } \\
\text { ECT: } 14 \\
\text { TMS: } 14\end{array}$ & $\begin{array}{l}\text { Electroconvulsive } \\
\text { therapy was } \\
\text { applied unilaterally } \\
\text { approximately three } \\
\text { times per week for } 2 \\
\text { to } 4 \text { weeks. }\end{array}$ & $\begin{array}{l}\text { rTMS was applied } \\
\text { in sessions } \\
\text { of } 1600 \text { stimuli at } \\
10 \text { Hertz and } 90 \% \\
\text { of motor threshold } \\
\text { intensity to the left } \\
\text { dorsolateral } \\
\text { prefrontal cortex. }\end{array}$ & \begin{tabular}{l|} 
HDRS \\
RVLT Total \\
Letter \\
Number \\
sequencing \\
subtest from \\
WMS-III \\
TNET
\end{tabular} & $\begin{array}{l}\text { ECT group received } \\
\text { ECT as an add-on to } \\
\text { their stable medication } \\
\text { regimen. } \\
\text { rTMS group underwent } \\
\text { a medication taper } \\
\text { and wash-out period; } \\
\text { received rTMS without } \\
\text { the adjunct of any other } \\
\text { medications. }\end{array}$ & $\begin{array}{l}\text { Findings suggest that } \\
\text { ECT is associated with } \\
\text { transient negative } \\
\text { cognitive side effects, } \\
\text { while deficits of this sort } \\
\text { are not apparent after } \\
\text { treatment with a 2-week } \\
\text { course of rTMS. }\end{array}$ \\
\hline $\begin{array}{l}\text { Schulze- } \\
\text { Rauschenbach } \\
\text { SC, et al. [14] }\end{array}$ & $\begin{array}{l}\text { Mean age (S.D): } \\
\text { ECT: } 46.7 \text { (11.0) } \\
\text { TMS: } 47.7(13.1) \\
\text { Control: } 48.9 \\
\text { N=45, ECT: } 14, \text { TMS: } \\
16 \\
\text { Control: } 14 \\
\text { Psychosis excluded; } \\
\text { all were treatment } \\
\text { resistant. }\end{array}$ & $\begin{array}{l}\text { RUL } \\
2-2.5 \times \text { ST } \\
\text { Meant treatments: } \\
9.9\end{array}$ & $\begin{array}{l}100 \% \text { MT } \\
\text { Pulse Frequency: } \\
10 \mathrm{~Hz} \\
\text { Pulse duration: } \\
2 \mathrm{sec} \\
\text { Mean Sessions: } \\
10.8\end{array}$ & $\begin{array}{l}\text { HDRS } \\
\text { BDI } \\
\text { Neuropsych } \\
\text { testing }\end{array}$ & $\begin{array}{l}\text { Medications not changed } \\
\text { during treatment } \\
\text { with ECT or TMS. } \\
\text { Antidepressants, low } \\
\text { potency neuroleptics and } \\
\text { non-benzodiazepines } \\
\text { hypnotics were } \\
\text { continued. }\end{array}$ & $\begin{array}{l}\text { No difference between } \\
\text { ECT and TMS groups, } \\
\text { response rate ( } 50 \% \\
\text { reduction in HDRS } \\
\text { scores) in the ECT group } \\
\text { was } 46 \% \text { and in the } \\
\text { TMS group was } 44 \% \text {, } \\
\text { with } p=0.90 \\
\text { TMS group had a } \\
\text { statistically superior } \\
\text { performance on } \\
\text { anterograde, retrograde } \\
\text { and subjective memory } \\
\text { measures. }\end{array}$ \\
\hline $\begin{array}{l}\text { Rosa MA, et al. } \\
\text { [25] }\end{array}$ & $\begin{array}{l}\text { Mean age (S.D): } \\
\text { ECT: } 46.0 \text { (10.6) } \\
\text { TMS: } 41.8 \text { (10.2) } \\
\text { N=40, ECT: } 15, \\
\text { TMS: } 20 \text { (5 excluded } \\
\text { after randomization; } \\
3 \text { in ECT and } 2 \text { in } \\
\text { TMS group) } \\
\text { Pt. with Psychosis } \\
\text { excluded. } \\
\text { Duration of illness } \\
\text { (months): } \\
110.7 \text { (TMS) } \\
103.6 \text { (ECT) } \\
\text { Duration of current } \\
\text { episode (weeks): } \\
11.5 \text { (TMS) } \\
10.5(E C T) \\
\text { Previous episodes: } \\
3.6 \text { (TMS) } \\
2.9 \text { (ECT) }\end{array}$ & $\begin{array}{l}\mathrm{RUL} \text {, switched to } \mathrm{BL} \\
\text { if no response after } \\
2 \text { weeks } \\
4.5 \times \mathrm{ST}\end{array}$ & $\begin{array}{l}\text { 100\% MT } \\
\text { Pulse Frequency: } \\
10 \mathrm{~Hz} \\
\text { Train Duration: } \\
10 \mathrm{sec} \\
\text { Pulses per session: } \\
2500 \\
\text { Total Sessions: } 20\end{array}$ & $\begin{array}{l}\text { HDRS } \\
\text { CGI } \\
\text { VAS } \\
\text { Neuropsych } \\
\text { testing }\end{array}$ & $\begin{array}{l}\text { Use of antidepressants, } \\
\text { antipsychotics and } \\
\text { mood stabilizers were } \\
\text { not permitted during } \\
\text { treatment period. } \\
\text { Washout period } \\
\text { was one week for } \\
\text { antidepressants, } 3 \text { weeks } \\
\text { for except fluoxetine, } \\
\text { and } 2 \text { weeks for MAOI. } \\
\text { Benzodiazepines were } \\
\text { used if necessary (PRN). }\end{array}$ & $\begin{array}{l}\text { ECT and TMS were } \\
\text { equivalent on ITT } \\
\text { ANCOVA on all } \\
\text { measures. Response } \\
\text { rate ( } 50 \% \text { reduction in } \\
\text { HDRS scores) for the ECT } \\
\text { group was } 30 \% \text { and for } \\
\text { the TMS group } 45 \% \text {, } \\
\text { with p } 0.35 \\
\text { Remission rate (HDRS } \\
<7) \text { for the ECT group } \\
\text { was } 15 \% \text { and for the } \\
\text { TMS group was } 9 \%, \text { with } \\
p=0.65 \\
\text { No difference between } \\
\text { ECT and TMS groups } \\
\text { on neuropsychological } \\
\text { tests. }\end{array}$ \\
\hline
\end{tabular}




\begin{tabular}{|c|c|c|c|c|c|c|}
\hline $\begin{array}{l}\text { Eranti S, et al. } \\
\text { [26] }\end{array}$ & $\begin{array}{l}\text { Mean age (S.D): } \\
\text { ECT: } 68.3 \text { (13.4) } \\
\text { TMS: } 63.6 \text { (17.3) } \\
\text { N=46, ECT: } 24 \text { (18 } \\
\text { completed), TMS: } 22 \\
\text { Psychosis: ECT: } 4, \\
\text { TMS: } 3 \\
\text { Duration of current } \\
\text { episode } \\
\text { (weeks): } \\
24.4 \text { (ECT) } \\
30.8 \text { (TMS) } \\
\text { Previous episodes: } \\
3.7 \text { (TMS) } \\
4.2 \text { (ECT) }\end{array}$ & \begin{tabular}{|l|} 
UL switched to BL \\
$1.5 \times \mathrm{ST}(\mathrm{BL})$ \\
$2.5 \times \mathrm{ST}(\mathrm{UL})$ \\
Continued until \\
improvement \\
Total sessions? Upto \\
10
\end{tabular} & $\begin{array}{l}110 \% \mathrm{MT} \\
\text { Pulse Frequency: } \\
10 \mathrm{~Hz} \\
\text { Train Duration: } \\
5 \mathrm{sec} \\
\text { Trains per session } \\
15000 \\
\text { Total Sessions } 15\end{array}$ & $\begin{array}{l}\text { HDRS } \\
\text { BDI } \\
\text { VAS } \\
\text { BPRS } \\
\text { CAMCOG } \\
\text { MMSE }\end{array}$ & $\begin{array}{l}\text { Patients continued } \\
\text { their psychotropic } \\
\text { medications. No changes } \\
\text { were made. }\end{array}$ & $\begin{array}{l}\text { ECT was superior to } \\
\text { TMS in Intention to } \\
\text { Treat (ITT) analysis } \\
\text { of covariance on all } \\
\text { depression measures. } \\
\text { For HDRS Effect Size } \\
\text { was } 1.44 \text { ( } p=0.002) .13 \\
\text { patients }(59.1 \% \text { ) from } \\
\text { ECT met remission } \\
\text { criteria (HDRS }<8 \text { ), while } \\
\text { only } 4 \text { patients (16.7\%) } \\
\text { form TMS group met } \\
\text { remission criteria. } \\
\text { Included psychotic } \\
\text { patients } \\
\text { still produced superior } \\
\text { results for ECT } \\
\text { (remission rate of } 63.2 \\
\% \text { vs. } 15.8 \% \text {, } p=0.007 \text { ). } \\
\text { No significant } \\
\text { differences between } \\
\text { ECT and TMS group on } \\
\text { CAMCOG, MMSE scoring }\end{array}$ \\
\hline $\begin{array}{l}\text { Mcloughlin DM, } \\
\text { et al. [10] }\end{array}$ & $\begin{array}{l}\text { Mean Age: N/A } \\
\text { N=46 } \\
\text { ECT: } 22 \\
\text { TMS: } 24\end{array}$ & \begin{tabular}{|l|} 
Stimulus dosing \\
method, 1.5 times \\
seizure threshold, \\
course length \\
decided by referring \\
physician
\end{tabular} & $\begin{array}{l}15 \text { day course, } \\
\text { rTMS on left } \\
\text { DLPFC, } 20 \text { trains } \\
\text { per day, } 5 \text { seconds } \\
\text { at } 10 \mathrm{~Hz}, 110 \% \text { of } \\
\text { motor threshold }\end{array}$ & $\begin{array}{l}\text { 17-item } \\
\text { Hamilton } \\
\text { Depression } \\
\text { Rating Scale } \\
\text { (HAM-D) } \\
\text { Beck } \\
\text { Depression } \\
\text { Inventory-II } \\
\text { and visual } \\
\text { analogue } \\
\text { Brief } \\
\text { Psychiatric } \\
\text { Rating Scale } \\
\text { (BPRS) score } \\
\text { Quality- } \\
\text { Adjusted Life } \\
\text { Years (QALYS) }\end{array}$ & $\begin{array}{l}\text { Both groups continued } \\
\text { to receive standard } \\
\text { treatment prescribed by } \\
\text { referring physician and } \\
\text { care team }\end{array}$ & $\begin{array}{l}\text { rTMS was not as } \\
\text { effective as ECT. } \\
\text { ECT was substantially } \\
\text { more effective for the } \\
\text { short-term treatment of } \\
\text { depression. }\end{array}$ \\
\hline $\begin{array}{l}\text { Knapp M, et al. } \\
\text { [27] }\end{array}$ & $\begin{array}{l}\text { Mean Age (S.D): } \\
\text { ECT: } 68 \text { (13) } \\
\text { TMS: } 64 \text { (17) } \\
\text { N=46 } \\
\text { ECT: } 22 \\
\text { TMS: } 24\end{array}$ & $\begin{array}{l}\text { UL switched to BL } \\
1.5 \times \mathrm{ST}(\mathrm{BL}) \\
2.5 \times \mathrm{ST}(\mathrm{UL}) \\
\text { Continued until } \\
\text { improvement } \\
\text { Total sessions? } \\
\text { Range } 2-10\end{array}$ & $\begin{array}{l}\text { 110\% MT } \\
\text { Pulse Frequency: } \\
10 \mathrm{~Hz} \\
\text { Train Duration: } \\
5 \mathrm{sec} \\
\text { Pulses per session: } \\
15000 \\
\text { Total Sessions: } 15\end{array}$ & $\begin{array}{l}\text { HDRS } \\
\text { SF6D }\end{array}$ & $\begin{array}{l}\text { No medication changes } \\
\text { were made during the } \\
\text { study. }\end{array}$ & $\begin{array}{l}\text { The cost-effectiveness } \\
\text { acceptability curves } \\
\text { indicated that there is } \\
\text { a very small probability } \\
\text { that rTMS is more cost- } \\
\text { effective than ECT. }\end{array}$ \\
\hline $\begin{array}{l}\text { Keshtkar M, et } \\
\text { al. [28] }\end{array}$ & $\begin{array}{l}\text { Mean Age: } \\
\text { ECT: } 35.6 \\
\text { TMS: } 34, N=73 \\
\text { This trial analyzed } \\
\text { the antidepressant } \\
\text { effects of ECT and } \\
\text { rTMS in } 73 \text { patients } \\
\text { with TRD. }\end{array}$ & $\begin{array}{l}\text { BL } 10 \text { sessions } \\
\text { brief-pulse, square- } \\
\text { wave, constant } \\
\text { current (pulse width: } \\
1.4 \text { milliseconds; } \\
\text { duration: } 1.25 \\
\text { seconds; frequency: } \\
80 \mathrm{~Hz} \text {; current: } 0.8 \\
\text { amp) }\end{array}$ & $\begin{array}{l}\text { Active rTMS } \\
\text { via magnetic } \\
\text { stimulator session } \\
\text { lasting } 10 \text { minutes } \\
\text { ( } 408 \text { stimulations } \\
\text { for each session, } \\
\text { a total of } 4080 \text { for } \\
\text { each patient). } \\
\text { Left DLPFC } \\
90 \% \text { of the resting } \\
\text { motor threshold } \\
10 \text {-day course. }\end{array}$ & $\begin{array}{l}\text { HDRS } \\
\text { BDI }\end{array}$ & $\begin{array}{l}\text { Patients taking } \\
\text { antidepressants and } \\
\text { sedatives } \\
\text { excluded from the study. }\end{array}$ & $\begin{array}{l}\text { Both ECT and rTMS } \\
\text { significantly improved } \\
\text { depression and suicidal } \\
\text { behavior scores. } \\
\text { However, ECT reduced } \\
\text { depression and suicidal } \\
\text { behavior scores more } \\
\text { than rTMS. There were } \\
\text { no significant adverse } \\
\text { effects in the rTMS } \\
\text { group reported. }\end{array}$ \\
\hline
\end{tabular}


Table 2: Combined effect size for ECT and rTMS studies- fixed and random effect model.

\begin{tabular}{|l|c|c|c|c|c|}
\hline \multicolumn{1}{|c|}{ Method } & Estimate & SE & $\mathbf{9 5 \%} \mathbf{C l}$ & $\mathbf{z}$ & p-value \\
\hline Fixed effect & 0.2802 & 0.5732 & $\begin{array}{c}{[-0.8432,} \\
1.4037]\end{array}$ & 0.4889 & 0.6249 \\
\hline $\begin{array}{l}\text { Random } \\
\text { effect }\end{array}$ & 1.1958 & 1.4752 & $\begin{array}{c}{[-1.6956,} \\
4.0871]\end{array}$ & 0.8106 & 0.4176 \\
\hline
\end{tabular}

Additional research needed to shed light on the cognitive side effects of ECT and rTMS.

\section{Standardization of treatment protocol}

Authors noticed variation in treatment protocol in the selected studies; therefore, contribution of psychotropic meds in improving depression symptoms is an unclear area for future research. For instance, some studies [24,26] allowed participants in the ECT group to continue their psychotropic medications while participants in rTMS group were restricted. In one study, 12 participants were drug free. Therefore, contribution of psychotropic meds in improving depression symptoms in addition to ECT and rTMS is unclear.

It should be noted that in previous studies use of rTMS in clinical setting has been limited; there are many parameters, both treatment and patient related, that may affect the clinical outcome. TMS methods (e.g. coil placement, stimulus intensity and number of treatments etc.) have not been standardized yet [33].

\section{Gender differences}

One interesting observation that was noticed in this metaanalysis was the gender differences. In approximately $40 \%$ of RCTs, more females were allocated to receive ECT and rTMS than males $[17,22,27,28]$. Moreover, a higher percentage of participants were enrolled in the rTMS group versus in the ECT group. This could be due to individual patient preference, or a higher prevalence of TRD among women. Further research on gender difference would highlight the importance of variation in response rate between males and females.

\section{Conclusion}

To conclude, TRD continues to be a significant clinical challenge. Based on the literature review, it is much more complicated than that, and maybe the superiority of ECT on rTMS is only applicable to a specific population under specific conditions.

Overall, the findings from this review indicated- TRD continues to be a significant clinical challenge. The heterogeneity of the specific patient populations and study designs makes it more challenging to compare these therapies directly. There is a pressing need for largescale, adequately powered studies to draw definite conclusions.

It has been learned from previous ECT studies that over the period from 1940 to the present, that ECT has been well replicated and that the electrode placement and electrical stimulus parameters have a significant effect on the efficacy of ECT. With the FDA's approval, we expect to learn more about rTMS safety, tolerability, efficiency, and therapeutic potential for TRD. Additionally, rTMS methods (e.g., coil placement, stimulus intensity, and the number of treatments) should be more rigorously standardized. If proven efficacious, rTMS would provide an important treatment option for not only patients with TRD but in the treatment of other psychiatric disorders, including schizophrenia and anxiety disorders.

Although each of these treatments has been studied in patients with TRD, the overall heterogeneity of the specific patient populations and study designs makes it more challenging to compare these therapies directly. There is a pressing need for large-scale, adequately powered studies to draw definite conclusions.

\section{Disclosure Statement}

The authors have no conflict of interest to report.

\section{Acknowledgment}

We would like to thank Vinay Kumar and Paras Chand for their assistance with the literature search, editing, and proofreading of this manuscript.

\section{References}

1. Sackeim HA (2001) The definition and meaning of treatmentresistant depression. J Clin Psychiatry 62: 10-17.

2. Chang J, Chu Y, Ren Y, Li C, Wang Y, et al. (2020) Maintenance treatment of Transcranial Magnetic Stimulation (TMS) for treatmentresistant depression patients responding to acute TMS treatment. Int J Physiol Pathophysiol Pharmacol 12: 128-133.

3. O'Reardon JP, Solvason HB, Janicak PG, Sampson S, Isenberg KE, et al. (2007) Efficacy and safety of transcranial magnetic stimulation in the acute treatment of major depression: A multisite randomized controlled trial. Biol Psychiatry 62: 1208-1216.

4. Nordenskjold A (2015) ECT is superior to pharmacology for the short-term treatment of medication resistant in patients with bipolar depression. Evid Based Mental Health 18: 118.

5. Young AS, Klap R, Shoai R, Wells KB (2008) Persistent depression and anxiety in the United States: Prevalence and quality of care. Psychiatr Serv 59: 1391-1398.

6. Mathew SJ (2008) Treatment-resistant depression: recent developments and future directions. Depress Anxiety 25: 989-992.

7. Fava M (2003) Diagnosis and definition of treatment-resistant depression. Biol Psychiatry 53: 649-659.

8. Huynh NN, McIntyre RS (2008) What are the implications of the $\mathrm{STAR}^{*} \mathrm{D}$ trial for primary care? A review and synthesis. Prim Care Companion J Clin Psychiatry 10: 91-96.

9. Ren J, Li H, Palaniyappan L, Liu H, Wang J, et al. (2014) Repetitive transcranial magnetic stimulation versus electro-convulsive therapy for major depression: a systematic review and meta-analysis. Prog Neuropsychopharmacol Biol Psychiatry 51: 181-189.

10. McLoughlin DM, Mogg A, Eranti S, Pluck G, Purvis R, et al. (2007) The clinical effectiveness and cost of repetitive transcranial magnetic stimulation versus electro-convulsive therapy in severe depression: a multicentre pragmatic randomised controlled trial and economic analysis. Health Technol Assess 11: 1-54.

11. Rose D, Wykes T, Leese M (2003) Patients' perspectives on electroconvulsive therapy: Systematic review. BMJ 326: 1363.

12. Fraser LM, O'Carroll RE, Ebmeier KP (2008) The effect of electroconvulsive therapy on autobiographical memory: A systematic review. J ECT 24: 10-17.

13. Sackeim HA, Prudic J, Nobler MS, Fitzsimons L, Lisanby SH, et al. (2008) Effects of pulse width and electrode placement on the efficacy and cognitive effects of electroconvulsive therapy. Brain Stimul 1: 71-83.

14. Schulze-Rauschenbach SC, Harms U, Schlaepfer TE, Maier W, Falkai $P$, et al. (2005) Distinctive neurocognitive effects of repetitive transcranial magnetic stimulation and electro-convulsive therapy in major depression. Br J Psychiatry 186: 410-416. 
15. Barker AT, Jalinous R, Freeston IL (1985) Non-invasive magnetic stimulation of human motor cortex. Lancet 1: 1106-1107.

16. Grunhaus L, Dannon PN, Schreiber S, Dolberg OH, Amiaz R, et al. (2000) Repetitive transcranial magnetic stimulation is as effective as electro-convulsive therapy in the treatment of nondelusional major depressive disorder: an open study. Biol Psychiatry 47: 314-324.

17. UK ECT Review Group (2003) ECT Review Group Efficacy and safety of electro-convulsive therapy in depressive disorders: a systematic review and meta-analysis. Lancet 361: 799-808.

18. Weiner RD (1984) Does ECT cause brain damage? Behavioral Brain Sciences 7: 1-22.

19. Vallejo-Torres L, Castilla I, González N, Hunter R, Serrano-Pérez $P$, et al. (2015) Cost-effectiveness of electro-convulsive therapy compared to repetitive transcranial magnetic stimulation for treatment-resistant severe depression: a decision model. Psychol Med 45: 1459-1470.

20. Borenstein M, Hedges LV, Higgins JPT, Rothstein HR (2010) A basic introduction to fixed-effect and random-effects models for metaanalysis. Res Synth Methods 1: 97-111.

21. Pridmore S, Bruno R, Turnier-Shea Y, Reid P, Rybak M (2000) Comparison of unlimited numbers of rapid transcranial magnetic stimulation (rTMS) and ECT treatment sessions in major depressive episode. Int J Neuro-psychopharmacol 3: 129-134.

22. Janicak PG, O'Reardon JP, Sampson SM, Husain MM, Lisanby SH, et al. (2008) Transcranial magnetic stimulation in the treatment of major depressive disorder: A comprehensive summary of safety experience from acute exposure, extended exposure, and during reintroduction treatment. J Clin Psychiatry 69: 222-232.

23. Grunhaus L, Schreiber S, Dolberg OT, Polak D, Dannon PN (2003) A randomized controlled comparison of electroconvulsive therapy and repetitive transcranial magnetic stimulation in severe and resistant nonpsychotic major depression. Biol Psychiatry 53: 324-331.

24. O'Connor M, Brenninkmeyer C, Morgan A, Bloomingdale K, Thal $M$, et al. (2003) Relative Effects of Repetitive Transcranial Magnetic Stimulation and Electroconvulsive Therapy on Mood and Memory: A Neurocognitive Risk-Benefit Analysis. Cogn Behav Neurol 16: 118127
25. Rosa MA, Gattaz WF, Pascual-Leone A, Fregni F, Rosa MO, et al. (2006) Comparison of repetitive transcranial magnetic stimulation and electroconvulsive therapy in unipolar non-psychotic refractory depression: a randomized, single-blind study. Int J Neuropsychopharmacol 9: 667-676.

26. Eranti S, Mogg A, Pluck G, Landau S, Purvis R, et al. (2007) A randomized, controlled trial with 6-month follow-up of repetitive transcranial magnetic stimulation and electro-convulsive therapy for severe depression. Am J Psychiatry 164: 73-81.

27. Knapp M, Romeo R, Mogg A, Eranti S, Pluck G, et al. (2008) Costeffectiveness of transcranial magnetic stimulation vs. electroconvulsive therapy for severe depression: A multi-centre randomised controlled trial. J Affect Disord 109: 273-285.

28. Keshtkar M, Ghanizadeh A, Firoozabadi A (2011) Repetitive transcranial magnetic stimulation versus electro-convulsive therapy for the treatment of major depressive disorder, a randomized controlled clinical trial. J ECT 27: 310-314.

29. Davenport L (2020) ECT more effective for psychotic vs. nonpsychotic depression. Medscape Medical News.

30. Bagby RM, Ryder AG, Schuller DR, Marshall MB (2004) The Hamilton Depression Rating Scale: has the gold standard become a lead weight? Am J Psychiatry 161: 2163-2177.

31. Magnezi R, Aminov E, Shmuel D, Dreifuss M, Dannon P (2016) Comparison between neurostimulation techniques repetitive transcranial magnetic stimulation vs. electro-convulsive therapy for the treatment of resistant depression: patient preference and costeffectiveness. Patient Prefer Adherence 10: 1481-1487.

32. Edwards BC, Lambert MJ, Moran PW, McCully T, Smith KC, et al. (1984) A meta-analytic comparison of the Beck Depression Inventory and the Hamilton Rating Scale for Depression as measures of treatment outcome. Br J Clin Psychol 23: 93-99.

33. Maeda F, Keenan JP, Tormos JM, Topka H, Pascual-Leone A (2000) Modulation of corticospinal excitability by repetitive transcranial magnetic stimulation. Clin Neurophysiol 111: 800-805. 